\title{
The extent of leprosy-related disabilities in Istanbul Leprosy Hospital, Turkey
}

\author{
T. ÇAKINER,*‡ A. YÜKSEL, A. ŞENAL EĞİT,* \\ G. ÇAĞRI,* M. KARAÇORLU,† \& A. KÜLTÜR \\ *Department of Ophthalmology, and the Department of Physio- \\ therapy, Istanbul Leprosy Research Center, Istanbul, Turkey; †Eye \\ Diseases Research Center, Istanbul University, Istanbul, Turkey
}

Accepted for publication 6 June 1996

Summary This study was carried out between January and December 1992 at the Istanbul Leprosy Hospital. Seven hundred and eleven leprosy patients were evaluated according to their age, gender and type of disease and disability according to the WHO disability grading system (1980). There were 527 males (74.2\%) and 184 females $(25.8 \%)$ in the group. The average age was $50.0 \pm 13.5$ years and the average duration of disease was $25.9 \pm 13 \cdot 2$ years. Six hundred and seventy-eight patients (95.4\%) were in borderline (BL) and lepromatous (LL) leprosy.

The extent of disabilities was very high in 711 leprosy patients. It was found that 539 of the patients $(75.8 \%)$ had eye disabilities, 511 of them $(71.8 \%)$ had hand disabilities, 521 of them (73.3\%) had foot disabilities.

The most frequent eye, hand and foot disabilities were a decrease of vision (52.7), acute or chronic iridocyclitis (48.8\%), slightly-marked corneal sensory loss (43.2\%), mobile claw hand $(33.3 \%)$, palmar insensitivity $(16.3 \%)$, plantar ulcer $(37.2 \%)$ and plantar insensitivity $(19 \cdot 8 \%)$.

Eye deformities were the most common of the three affected areas in this study.

\section{Introduction}

Leprosy is a chronic infectious disease caused by Mycobacterium leprae and commonly affects the peripheral nerves and the skin. It may produce deformities and disabilities which result in permanent damage for the patients causing stigma. ${ }^{1}$

The Istanbul Leprosy Hospital is run by the Medical Faculty of Istanbul University, The Association for Fight Against Leprosy and the Ministry of Health. Besides 60 beds, there is a laboratory with skin-smear facilities, an operating theatre, a rehabilitation service, a dressing unit, an eye unit, a shoe workshop, a social department, a dental unit and handicraft shops. An ophthalmologist, a surgeon and four dermatologists work in Istanbul Leprosy Hospital. There 
is also an outpatient clinic attached to the hospital. The leprosy dispensary located inside Istanbul Leprosy Hospital gives priority to the routine control of all the patients living in Istanbul and neighbouring cities. These are reviewed at the Dispensary at 6-month intervals if they are under leprosy therapy, and annually if they have completed the therapy. Patients with problems are admitted to the leprosy hospital. The reasons for hospitalization according to the records of 1991 are determined as $25.7 \%$ medical control, $29.9 \%$ hand or foot care, $18.7 \%$ eye problems, $10.5 \%$ treatment modulation in newly-diagnosed patients, $5.0 \%$ reaction and $9.7 \%$ surgical procedure. ${ }^{2}$

In 1991 according to the Ministry of Health Records, of the 3319 leprosy patients 2659 have been seen by the staff of Istanbul Leprosy Hospital, 1058 having come to the hospital for various reasons. Seven hundred and eleven of the 1058 are included in this study.,3

The aim of this study was to detect the percentage of leprosy-related eye, hand and foot disabilities in Istanbul Leprosy Hospital, Turkey.

\section{Materials and methods}

This study in which the patients themselves were questioned about the duration of the disease was carried out in the period January-December 1992. Two hundred and thirteen of 711 leprosy cases were under treatment and 114 were being given multidrug therapy (MDT).

Seven hundred and eleven leprosy patients were evaluated according to their age, gender and type of disease. The diagnosis of leprosy was verified by the case history, clinical and bacteriologic tests done in the Istanbul Leprosy Hospital. These cases were classified by the Ridley-Jopling classification. ${ }^{4}$

Most of the 711 patients were diagnosed previously. Reasons for coming to the hospital were general control, eye, hand and foot disabilities as well as social problems.

\section{OPHTHALMIC EXAMINATIONS}

Ophthalmic examination of all patients were done by experienced nurses under the ophthalmologist's supervision in the Eye Department. The Snellen Chart was used for vision assessment; $2 / 10$ and over were evaluated as mild and moderate visual loss; $1 / 10$ and under as severe visual loss and blindness. Lagophthalmos degrees and ectropium of the patients were recorded. Cochet-Bonnet aesthesiometer was used for corneal sensitivity measurement. The cornea divided into four quadrants and one central area. The examination began with $60 \mathrm{~mm}$ of filament and was continued by shortening the filament by $5 \mathrm{~mm}$, until the patient responded that he did not feel the contact of the filament. The average of measurements performed on cornea in 5 different areas by aesthesiometer were calculated; $55 \mathrm{~mm}$ and less was evaluated as loss of sensation. Slit lamp (Haag-Streit) was used as the examination for cornea, anterior chamber, iris, pupil and lens. $1980^{5}$

Eye disability was also assessed according to the WHO disability grading system

\section{HAND AND FOOT EXAMINATION}

Hand and foot examinations were done by 2 physiotherapists and 3 experienced physiotherapy nurses. WHO disability grading system (1980) was used for assessment. ${ }^{5}$ 
Table 1. Type of leprosy

\begin{tabular}{|c|c|c|c|c|c|c|}
\hline \multirow[b]{2}{*}{ Type } & \multicolumn{2}{|c|}{ Female } & \multicolumn{2}{|c|}{ Male } & \multicolumn{2}{|c|}{ Total } \\
\hline & $n$ & $\%$ & $n$ & $\%$ & $n$ & $\%$ \\
\hline LL & 122 & $66 \cdot 3$ & 352 & $66 \cdot 8$ & 474 & $66 \cdot 7$ \\
\hline BL & 55 & $29 \cdot 9$ & 149 & $28 \cdot 3$ & 204 & $28 \cdot 7$ \\
\hline BT & 5 & $2 \cdot 7$ & 25 & $4 \cdot 7$ & 30 & $4 \cdot 2$ \\
\hline $\mathrm{TT}$ & 2 & $1 \cdot 1$ & 1 & $0 \cdot 2$ & 3 & $0 \cdot 4$ \\
\hline Total & 184 & $100 \cdot 0$ & 527 & $100 \cdot 0$ & 711 & $100 \cdot 0$ \\
\hline
\end{tabular}

For statistical analysis the statistical programme EPI-Info 5 (Atlanta, Georgia, WHO$\mathrm{CDC}$ ) was used.

\section{Results}

The study consisted of 527 males $(74 \cdot 1 \%)$ and 184 females $(25 \cdot 9 \%)$. The average age of the group was $50 \cdot 0 \pm 13 \cdot 5$ years (females: $50 \cdot 3 \pm 14 \cdot 2$; males: $49 \cdot 9 \pm 13 \cdot 2$ ). The average duration of the disease was $25 \cdot 9 \pm 13 \cdot 2$ years (females: $25 \cdot 4 \pm 13 \cdot 2$; males: $26 \cdot 1 \pm 13 \cdot 3$ ). The ratio of male to female was $2: 8$.

Six hundred and seventy-eight leprosy patients $(95.4 \%)$ were borderline (BL) and lepromatous leprosy (LL) in our study (Table 1).

Four hundred and eighteen $(58.8 \%)$ of the leprosy cases were hospitalized once, 245 (34\%) twice, $33(4.6 \%)$ three times and $15(2.2 \%)$ four times or more. When the duration of hospitalization was analysed, 312 cases $(43.0 \%)$ were determined as being hospitalized for 1-30 days, 253 cases (35.6\%) for 31-90 days, 83 cases (11.7\%) for 91-180 days and 63 cases $(8 \cdot 8 \%)$ for more than 181 days.

Table 2 shows the number and percentage of patients with disabilities among the 711 leprosy patients in The Istanbul Leprosy Hospital; $546(76.8 \%)$ of the total number of patients were found to have one or more disabilities, $165(23.2 \%)$ of the total patients did not have any disabilities related to leprosy.

Twenty-five $(75 \cdot 75 \%)$ of tuberculoid (TT) and borderline-tuberculoid (BT) leprosy cases, $252(77.3 \%)$ of BL cases, 269 of LL cases $(76.4 \%)$ had more than one of the eye, hand or foot disabilities.

Table 2. Percentage of patients with deformities amongst 711 leprosy patients

\begin{tabular}{|c|c|c|c|c|c|c|}
\hline \multirow[b]{2}{*}{ Deformity/No. deformity } & \multicolumn{2}{|c|}{ Female } & \multicolumn{2}{|c|}{ Male } & \multicolumn{2}{|c|}{ Total } \\
\hline & $n$ & $\%$ & $n$ & $\%$ & $n$ & $\%$ \\
\hline Deformity absent & 39 & $21 \cdot 2$ & 126 & 23.9 & 165 & $23 \cdot 2$ \\
\hline Deformity present & 145 & $78 \cdot 8$ & 401 & $76 \cdot 1$ & 546 & $76 \cdot 8$ \\
\hline Total & 184 & $100 \cdot 0$ & 527 & $100 \cdot 0$ & 711 & $100 \cdot 0$ \\
\hline
\end{tabular}


Table 3. The total disabilities found in eyes, hand and feet according to sexes

\begin{tabular}{|c|c|c|c|c|c|c|}
\hline \multirow[b]{2}{*}{ Types of deformity } & \multicolumn{2}{|c|}{ Female } & \multicolumn{2}{|c|}{ Male } & \multicolumn{2}{|c|}{ Total } \\
\hline & $n$ & $\%$ & $n$ & $\%$ & $n$ & $\%$ \\
\hline Eyes & 145 & $78 \cdot 8$ & 394 & $74 \cdot 8$ & 539 & $75 \cdot 8$ \\
\hline Hands & 127 & $69 \cdot 0$ & 384 & $72 \cdot 9$ & 511 & $71 \cdot 8$ \\
\hline Feet & 120 & $65 \cdot 2$ & 401 & $76 \cdot 1$ & 521 & $73 \cdot 3$ \\
\hline
\end{tabular}

Table 4. Eye disability grading (WHO 1980)

\begin{tabular}{|c|c|c|c|c|c|c|}
\hline \multirow[b]{2}{*}{ Disability grade } & \multicolumn{2}{|c|}{ Female } & \multicolumn{2}{|c|}{ Male } & \multicolumn{2}{|c|}{ Total } \\
\hline & $n$ & $\%$ & $n$ & $\%$ & $n$ & $\%$ \\
\hline 0 & 39 & $21 \cdot 2$ & 133 & $25 \cdot 2$ & 172 & $24 \cdot 2$ \\
\hline 1 & 35 & $19 \cdot 0$ & 91 & $17 \cdot 3$ & 126 & $17 \cdot 7$ \\
\hline 2 & 98 & $53 \cdot 3$ & 251 & $47 \cdot 6$ & 349 & $49 \cdot 1$ \\
\hline 3 & 12 & $6 \cdot 5$ & 52 & $9 \cdot 9$ & 64 & $9 \cdot 0$ \\
\hline Total & 184 & $100 \cdot 0$ & 527 & $100 \cdot 0$ & 711 & $100 \cdot 0$ \\
\hline
\end{tabular}

Grade: 0 , no eye problem due to leprosy, no evidence of visual loss;

1 , mild visual loss (7-9/10), mild loss of corneal sensation, orbicularis oculi muscle weakens (not lagophthalmos);

2 , lagophthalmos, iridocyclitis, keratitis, VA $>6 / 60$; and

3 , severe visual impairment, blindness.

Table 3 shows the total disabilities found in the eyes, hands and feet according to gender. Among eye, hand and foot disabilities the highest number was found in eyes $(75.8 \%)$, followed by foot and hand disabilities, respectively $(73 \cdot 3 \%, 71 \cdot 8 \%)$.

There was no statistically significant difference between the genders in eye, hand and foot disabilities $(p>0 \cdot 05)$.

Table 5. Hand disability grading ${ }^{5}$

\begin{tabular}{|c|c|c|c|c|c|c|}
\hline \multirow[b]{2}{*}{ Disability grade } & \multicolumn{2}{|c|}{ Female } & \multicolumn{2}{|c|}{ Male } & \multicolumn{2}{|c|}{ Total } \\
\hline & $n$ & $\%$ & $n$ & $\%$ & $n$ & $\%$ \\
\hline 0 & 57 & $31 \cdot 0$ & 143 & $27 \cdot 1$ & 200 & $28 \cdot 2$ \\
\hline 1 & 28 & $15 \cdot 2$ & 88 & $16 \cdot 7$ & 116 & $16 \cdot 2$ \\
\hline 2 & 60 & $38 \cdot 0$ & 198 & $37 \cdot 6$ & 268 & $37 \cdot 7$ \\
\hline 3 & 29 & $15 \cdot 8$ & 98 & $18 \cdot 6$ & 127 & $17 \cdot 9$ \\
\hline Total & 184 & $100 \cdot 0$ & 527 & $100 \cdot 0$ & 711 & $100 \cdot 0$ \\
\hline
\end{tabular}

Grade: 0 , no anesthesia or visible deformity or damage;

1 , loss of sensation;

2, ulcer, mobile claw hand, visible absorption; and

3 , drop hand, finger contracture, severe absorption. 
Table 6. Feet disability grading ${ }^{5}$

\begin{tabular}{|c|c|c|c|c|c|c|}
\hline \multirow[b]{2}{*}{ Disability grade } & \multicolumn{2}{|c|}{ Female } & \multicolumn{2}{|c|}{ Male } & \multicolumn{2}{|c|}{ Total } \\
\hline & $n$ & $\%$ & $n$ & $\%$ & $n$ & $\%$ \\
\hline 0 & 64 & $34 \cdot 8$ & 126 & $23 \cdot 9$ & 190 & $26 \cdot 7$ \\
\hline 1 & 34 & $18 \cdot 4$ & 107 & $20 \cdot 3$ & 141 & $19 \cdot 8$ \\
\hline 2 & 64 & $34 \cdot 8$ & 242 & $45 \cdot 9$ & 306 & $43 \cdot 1$ \\
\hline 3 & 22 & $12 \cdot 0$ & 52 & $9 \cdot 9$ & 74 & $10 \cdot 4$ \\
\hline Total & 185 & $100 \cdot 0$ & 527 & $100 \cdot 0$ & 711 & $100 \cdot 0$ \\
\hline
\end{tabular}

Grade: 0 , no anesthesia or visible deformity or damage;

1 , loss of sensation;

2, trophic ulcer, claw finger, drop foot, visible absorption; and

3 , contracture, severe absorption.

Table 4 shows eye disabilities according to WHO disability system. No eye involvement was found in 172 patients $(24 \cdot 2 \%), 126$ cases $(17 \cdot 7 \%)$ had Grade 1,349 cases $(49 \cdot 1 \%)$ had Grade 2, and 64 cases (9.0\%) had Grade 3 eye disabilities.

According to the WHO disability system, 200 patients $(28 \cdot 2 \%)$ had no hand disabilities;

Table 7. Eye, hand and feet disabilities in 711 patients

\begin{tabular}{|c|c|c|c|c|c|c|}
\hline \multirow[b]{2}{*}{ Disabilities } & \multicolumn{2}{|c|}{ Female } & \multicolumn{2}{|c|}{ Male } & \multicolumn{2}{|c|}{ Total } \\
\hline & $n$ & $\%$ & $n$ & $\%$ & $n$ & $\%$ \\
\hline \multicolumn{7}{|l|}{ Eye* } \\
\hline vision $6 / 6$ & 39 & $21 \cdot 2$ & 133 & $25 \cdot 2$ & 172 & $24 \cdot 2$ \\
\hline$>6 / 60$ & 133 & $72 \cdot 3$ & 342 & $64 \cdot 9$ & 475 & $66 \cdot 8$ \\
\hline$<6 / 60$ & 12 & $6 \cdot 5$ & 52 & $9 \cdot 9$ & 64 & $9 \cdot 0$ \\
\hline lagophthalmos & 64 & $34 \cdot 8$ & 231 & $43 \cdot 8$ & 295 & $41 \cdot 5$ \\
\hline ectropium & 53 & $28 \cdot 9$ & 231 & $43 \cdot 8$ & 284 & $40 \cdot 0$ \\
\hline corneal sensory loss & 56 & $30 \cdot 4$ & 251 & $47 \cdot 6$ & 307 & $43 \cdot 2$ \\
\hline keratitis & 46 & $25 \cdot 0$ & 151 & $28 \cdot 7$ & 197 & $27 \cdot 7$ \\
\hline iridocyclitis & 92 & $50 \cdot 0$ & 254 & $48 \cdot 2$ & 346 & $48 \cdot 7$ \\
\hline iris atrophy & 74 & $40 \cdot 2$ & 174 & $33 \cdot 0$ & 248 & $34 \cdot 9$ \\
\hline pupil deformity & 67 & $36 \cdot 4$ & 151 & $28 \cdot 7$ & 218 & $30 \cdot 7$ \\
\hline cataract & 37 & $20 \cdot 1$ & 179 & $34 \cdot 0$ & 216 & $30 \cdot 4$ \\
\hline \multicolumn{7}{|l|}{ Hand* } \\
\hline insensitivity & 28 & $15 \cdot 2$ & 88 & $16 \cdot 7$ & 116 & $16 \cdot 3$ \\
\hline mobile claw hand & 59 & $32 \cdot 0$ & 178 & $33 \cdot 7$ & 237 & $33 \cdot 3$ \\
\hline ulcer & 11 & $6 \cdot 1$ & 20 & $3 \cdot 8$ & 31 & $4 \cdot 4$ \\
\hline drop hand & 2 & $1 \cdot 1$ & 10 & $1 \cdot 8$ & 12 & $1 \cdot 7$ \\
\hline contracture & 15 & $8 \cdot 1$ & 46 & $8 \cdot 8$ & 61 & $8 \cdot 6$ \\
\hline severe absorption & 12 & $6 \cdot 6$ & 42 & $8 \cdot 1$ & 54 & $7 \cdot 6$ \\
\hline \multicolumn{7}{|l|}{ Foot* } \\
\hline insensitivity & 34 & $18 \cdot 4$ & 107 & 20.3 & 141 & $19 \cdot 8$ \\
\hline ulcer & 54 & $29 \cdot 3$ & 210 & $39 \cdot 9$ & 264 & $37 \cdot 2$ \\
\hline droop foot & 10 & $5 \cdot 5$ & 32 & $6 \cdot 0$ & 42 & $5 \cdot 9$ \\
\hline contracture & 12 & $6 \cdot 5$ & 25 & $4 \cdot 8$ & 37 & $5 \cdot 2$ \\
\hline severe absorption & 10 & $5 \cdot 5$ & 27 & $5 \cdot 1$ & 37 & $5 \cdot 2$ \\
\hline
\end{tabular}
Table.

* For each patient the most severe deformity of eye, hand or foot is counted in the 
116 patients $(16 \cdot 2 \%)$ had Grade 1 hand disabilities; 268 patients $(37 \cdot 7 \%)$ had Grade 2 ; and 127 patients (17.9\%) had Grade 3 (Table 5).

No foot disabilities were found in 190 patients $(26.7 \%)$. There were 141 patients $(19.8 \%)$ with Grade 1 foot disabilities; 306 patients $(43 \cdot 1 \%)$ with Grade 2; and 74 patients $(10 \cdot 4 \%)$ with Grade 3 (Table 6).

Table 7 shows the deformities of the eyes, hands and feet. The most frequent eye disabilities were a decrease of vision (539 or $75.8 \%$ ), acute or chronic iridocyclitis (346 or $48.7 \%$ ), slightly-marked corneal sensory loss (307 or $43 \cdot 2 \%$ ), lagophthalmos (295 or $41 \cdot 5 \%$ ) and ectropion ( 284 or $40.0 \%$ ). Superficial punctate keratitis was seen in 197 leprosy patients $(27 \cdot 7 \%)$. There were 218 patients $(30 \cdot 7 \%)$ with pupil deformity. Cataract was found in 216 cases $(30 \cdot 4 \%)$. Decrease of vision and iridocyclitis was the most common ocular complications encountered in both genders.

The most frequent disabilities of the hands and feet were mobile claw hand (237 or $33.3 \%)$, palmar insensitivity (116 or $16.3 \%)$, plantar ulcer (264 or $37.2 \%)$ and plantar insensitivity (141 or $19.8 \%)$.

Statistically there was a very significant relationship between age, and the duration of the disease and disability $(p<0.001)$.

\section{Discussion}

Seven hundred and eleven leprosy patients in our study made up of $21.4 \%$ of 3319 registered leprosy patients in Turkey.

In this study, we found that eye, hand and foot disabilities are very high being respectively, $75.8 \%, 71 \cdot 8 \%, 73.3 \%$. Several studies had reported the proportion of the disabilities in leprosy as follows: Guocheng ${ }^{6} 56 \cdot 9 \%$, Rao ${ }^{7} 42 \cdot 9 \%$, Iyere $38 \cdot 7 \%$, Zheng ${ }^{9}$ $67.5 \%$. Zheng did his study in leprosarium even though his result was lower than our result.

The most frequent disabilities were $75.8 \%$ decrease of vision, $48.7 \%$ iridocyclitis, $43.2 \%$ slightly-marked corneal sensory loss, $41.5 \%$ lagophthalmos $40.0 \%$ ectropion, $37.2 \%$ plantar ulcer, $19.8 \%$ claw hand and plantar insensitivity. In our study highly-decreased vision was found to be $9.0 \%$. This rate increases to $9.9 \%$ in males. Lagophthalmos, ectropion and decreased vision are higher in males compared to females. However iridocyclitis, iris atrophy and pupillary deformity were found to be higher in females compared to males (Table 7). No statistically significant difference of eye and hand disabilities was found between males and females. Foot disability occurs more in males than females $(p<0.05)$. This difference has been related to the fact that male patients work out of home. Iyere has reported the lagophthalmos rate to be $2.4 \%$, loss of corneal sensation to be $1.3 \%$, palmar insensitivity to be $17 \cdot 2 \%$ and plantar insensitivity to be $17 \cdot 9 \%,{ }^{8}$ Sehgal \& Srivastava have reported claw hands to be $19 \cdot 7 \% .{ }^{10}$ Karacorlu found various degrees of corneal loss of sensitivity in $46 \cdot 2 \%$ of leprosy patients. ${ }^{11}$

The disability rate was high in older age groups in our study $(p<0.001)$. This is similar to the result of Smith, ${ }^{12}$ Noordeen, ${ }^{13,14}$ Guocheng, ${ }^{6}$ Rao, ${ }^{7}$ and Zheng. ${ }^{9}$ It is considered that the duration of the disease is a more important factor than the age of patients in causing disabilities.

Noordeen reported that deformities were lower in females. ${ }^{13,14}$ Srinivasan \& Dharmandra said that nerve damage was seen to be lower in females. ${ }^{15}$ But, in the present study, there was no statistically difference between males and females $(p>0.05)$. 
The percentage of disability among patients is higher in Istanbul Leprosy Hospital, Turkey, than in some parts of the world. ${ }^{7-9,15}$ Among the reasons for these are a high percentage of multibacillary disease, prolonged duration of the disease, failure of the local health centre staff to treat patients regularly and insufficient care of patients. Medical personnel in our country are not very familiar with leprosy because of the low prevalence. This could lead to 5-10 years delay in diagnosis. ${ }^{16}$ During this time peripheral nerve damage develops leading to disabilities. ${ }^{1}$

\section{Conclusions}

Educating patients and medical personnel in the peripheral nerve disabilities and in the early symptoms of leprosy reactions would help prevent a high proportion of the disabilities and deformities. The organization of leprosy courses about leprosy complications for the health center personnel would also help. The reorganization of living conditions of the severely disabled patients according to their disabilities would prevent the progression of the disease. On this subject, studies are being continued in collaboration with the Ministry of Health, several universities and aid organizations in Turkey.

\section{References}

${ }^{1}$ Brandt PW, Fritschi EP. Rehabilitation in leprosy. In: Leprosy, 1st ed. Hastings RC (ed), Churchill Livingston Publishers. 1985; 237-319.

2 Istanbul Leprosy Hospital Statistics (1991).

3 The Year Book of Turkish Statistics (1993).

${ }^{4}$ Ridley DS, Jopling WH. Classification of leprosy according to immunity-a five group system. Int J Lepr, 1966; 34: 255-73.

5 World Health Organization. International classification of impairments, disabilities and handicaps. Geneva: WHO, 1980.

${ }^{6}$ Guocheng Z, Wenzhong L, Liangbin Y et al. An epidemiological survey of deformities and disabilities among 14257 cases of leprosy in 11 counties. Lepr Rev, 1993; 64: 143-49.

7 Rao PS, Karat S, Karat AB et al. Prevalence of deformities and disabilities among leprosy patients in an endemic area. Int J Lepr, 1970; 38: 1-11.

8 Iyere BB. Leprosy deformities: experience in Malai Leprosy Hospital, Maiduguri, Nigeria. Lepr Rev, 1990; 61: 171-9.

9 Zheng T, Zhengyong P, Huajie F et al. Disability survey in 1480 cases of leprosy. 13th International Leprosy Congress. 1988 Summary Book Fp.011, p. 15.

10 Sehgal VN, Srivastava G. HD deformities and disabilities: current status, Part II. The Star, 1988; 47(6): 8-11, 16.

11 Karacorlu MA, Cakiner T, Saylan T. Corneal sensitivity and correlations between decreased sensitivity and anterior segment pathology in ocular leprosy. Br J Ophthalmol, 1991; 75: 117-19.

12 Smith WCS, Antin US, Patole AR. Disability in leprosy: a relevant measurement of progress in leprosy control. Lepr Rev, 1980; 51: 55-66.

13 Noordeen SK, Srinavasan H. Epidemiology of disability in leprosy. Int J Lepr, 1966; 34: 159-69.

14 Noordeen SK, Srinavasan H. Epidemiology of disability in leprosy. Int J Lepr, 1966; 34: 170-4.

15 Srinavasan H, Dharmandra A. Deformities in leprosy: general considerations. In: Leprosy. Dharmendra (ed), Kothari Medical Publishing House, 1978, Chapter 27, p. 197.

16 Aytekin AH, Saylan T. Leprosy in Turkey. Lepr Rev, 1988; 59: 231-34. 